\title{
Impacts of Overweight and Obesity in Older Age on the Risk of Dementia: A Systematic Literature Review and a Meta-Analysis
}

\author{
Isaac M. Danat ${ }^{\mathrm{a}}$, Angela Clifford ${ }^{\mathrm{a}}$, Martin Partridge ${ }^{\mathrm{a}}$, Weiju Zhou ${ }^{\mathrm{a}}$, Aishat T. Bakre ${ }^{\mathrm{a}}$, \\ Anthony Chen ${ }^{\mathrm{b}}$, Danielle McFeeters ${ }^{\mathrm{a}}$, Tina Smith ${ }^{\mathrm{a}}$, Yuhui Wan ${ }^{\mathrm{c}}$, John Copeland ${ }^{\mathrm{d}}$, \\ Kaarin J. Anstey ${ }^{\mathrm{e}}$ and Ruoling Chen ${ }^{\mathrm{a}, *}$ \\ ${ }^{\mathrm{a}}$ Faculty of Education, Health and Wellbeing, University of Wolverhampton, Wolverhampton, UK \\ ${ }^{\mathrm{b}}$ Faculty of Sciences and Technology, Middlesex University, London, UK \\ ${ }^{\mathrm{c}}$ School of Public Health, Anhui Medical University, Hefei, Anhui, China \\ ${ }^{\mathrm{d}}$ Institute of Psychology, Health and Society, University of Liverpool, Liverpool, UK \\ ${ }^{\mathrm{e} S c h o o l ~ o f ~ P s y c h o l o g y, ~ U n i v e r s i t y ~ o f ~ N e w ~ S o u t h ~ W a l e s ~ a n d ~ N e u r o s c i e n c e ~ R e s e a r c h ~ A u s t r a l i a, ~ S y d n e y, ~ A u s t r a l i a ~}$
}

Accepted 3 December 2018

\begin{abstract}
.
Background: It is unclear whether overweight and obesity in older age reduces or increases the risk of incident dementia. Objective: To assess the impacts of overweight and obesity in older age on incident dementia.

Methods: We searched cohort studies reporting body weight measured in older age and dementia through PubMed, Embase, Medline, PyschInfo, and Cochrane library until July 2016. Sixteen articles were identified for the review. We pooled data from them and a new unpublished study from China, to calculate relative risk (RR) of incident dementia in relation to body mass index (BMI) and waist circumference (WC).

Results: All 16 cohort studies were undertaken in high income countries, with follow-up periods ranging between 3 to 18 years. Thirteen studies showed an inverse association between BMI and dementia, and three studies demonstrated a positive association. Pooled RR of dementia in relation to continuous BMI from 14 studied populations, including the new Chinese data, was 0.97 (95\% CI 0.95-1.00); in those followed up <9 years it was 0.95 (0.93-0.96) while in $\geq 9$ years follow-up it was 1.03 (0.96-1.11). In five studied populations examining categorical BMI, RR of dementia in older people classified as overweight and obese was $0.98(0.54-1.77)$ and $1.17(0.65-2.10)$ respectively, in comparison with other weights. The pooled WC data showed no association between increased WC and reduced risk of dementia.

Conclusion: The current evidence did not support a paradox on beneficial impacts of overweight and obesity in older age on incident dementia. More studies with long term follow up are needed to clarify the association of body weight in older age with dementia risk.
\end{abstract}

Keywords: Body weight, dementia, meta-analysis, older people

\section{INTRODUCTION}

Dementia is an age-related disease and remains a worldwide public health challenge as the aging

\footnotetext{
*Correspondence to: Professor Ruoling Chen, Centre for Health and Social Care Improvement (CHSCI), University of Wolverhampton, Wolverhampton, WV1 1DT, UK. Tel.: +44 1902 328622; Fax: +44 1902 321161; E-mail: r.chen@wlv.ac.uk.
}

population increases. The majority of dementia cases occur in older age, with over $90 \%$ of dementia cases developing after age 60 years and $32 \%$ in those $\geq 85$ years [1,2]. Although there is a significant association of overweight and obesity measured in younger and middle age with increased risk of incident dementia [3, 4], the contrary is found for most reported findings of overweight and obesity in older age 
$[5,6]$. Some studies [7] have reported that older people with obesity had a significantly reduced risk of incident dementia. Analysing a number of studies published before September 2014, Pedditizi et al. found that compared to those of normal weight, people classified as overweight or obese at $\geq 65$ years had a reduced risk of incident dementia; risk ratios were 0.88 (95\%CI 0.76-1.02) and 0.83 (0.74-0.94), respectively [6]. Knowledge surrounding the impact of body weight in older age on dementia risk has significant public health relevance and has the potential to lead to reductions in dementia worldwide. However, the conclusions from previous studies of older adults have been limited due to the combining of middle and older aged adults in samples for analysis [8]. The inverse association between incident dementia and overweight/obesity in older adults reported previously [6] was limited by the small number of studies including only older adults. Furthermore, previous systematic literature review studies [3] have not examined multiple indicators of obesity (e.g., waist circumference measurement) and have rarely included subgroup data analysis by duration of study follow-up to assess the inverse effect $[3,6]$. Over the past 3 years, following the debate on whether overweight/obesity in older age reduces the risk of late-life dementia [5, 6, 9] and a paradox on whether overweight would help survival longer than normal weight [10], there have been more studies [11-13] published on the association between overweight/obesity and incident dementia. In this paper, we carried out a comprehensive systematic literature review and meta-analysis to assess the impact of obesity and overweight measured by body mass index (BMI) and other indicators of central fat in older age on incident dementia. We added new data from an unpublished study in China to examine whether the length of the cohort follow-up affected the findings of the association between overweight/obesity in older age and incident dementia.

\section{METHODS}

\section{Systematic literature review}

We (ID, WZ, and AB) searched literature from Embase, Medline, PubMed, CINAHL, Psych-info, and Cochrane library databases. The strategy for the database search was developed using the Population, Exposure and Outcome framework [14, 15]. The search terms were ["dementia" OR "Alzheimer's, vascular dementia, cognitive impairment and cog- nitive decline"] AND ["BMI, 'Body Mass Index"” OR "Overweight, Obesity, Adiposity and Waist Circumference"] for all fields, including MeSH terms, abstract, title, or text words. The literature was searched from the earliest dates of each of the databases to 31 July 2016. The search for relevant articles included all studies with no language restriction. We read the title and abstract of the searched studies. The studies selected were appropriate for this review if they were prospective cohort studies that investigated incidence of all dementia (or any specific type of dementia) in relation to overweight or obesity measured by BMI or waist circumference (WC) in the population. The participants must be communitybased older adults with baseline age of $\geq 65$ years. Alongside the electronic database searches, a manual reference search was conducted to find additional articles missed by the online search. The grey literature was also explored and authors of eligible articles $[11,16]$ contacted by email for more information. Studies that assessed only cognitive impairment as an outcome with no formal diagnosis of dementia and those of cross-sectional and case control study designs were not included. We identified 16 original studies eligible for literature review (Fig. 1). Following the PRISMA guidelines [17], we conducted a systematic literature review. Each of the articles was reviewed by two reviewers (ID and AB/WZ) and assessed independently using a predesigned data extraction form to extract the necessary information from the chosen studies. Differences in reviewing literature and extracting data between the two reviewers were resolved through face-to-face discussion, and where the differences remained the 3 rd reviewer discussed with them to reach agreement. The quality assessment of the articles was conducted by employing the Newcastle-Ottawa Scale [18].

\section{Meta-analysis}

We took eligible data from the above identified studies and a new study from China [19]. We pooled data from each studied population in the paper, for all types of dementia first (if the studied population did not provide data of all dementia, its subtypes data would be used), and then for Alzheimer's disease $(\mathrm{AD})$ and vascular dementia $(\mathrm{VaD})$ separately for comparison where the data were available. The studied population was defined as each individual sample in the study according to its place, time (years) and person (gender, etc.) where applicable. Only reported relative risk (e.g., RRs, Hazard ratio, or Odds ratio) 


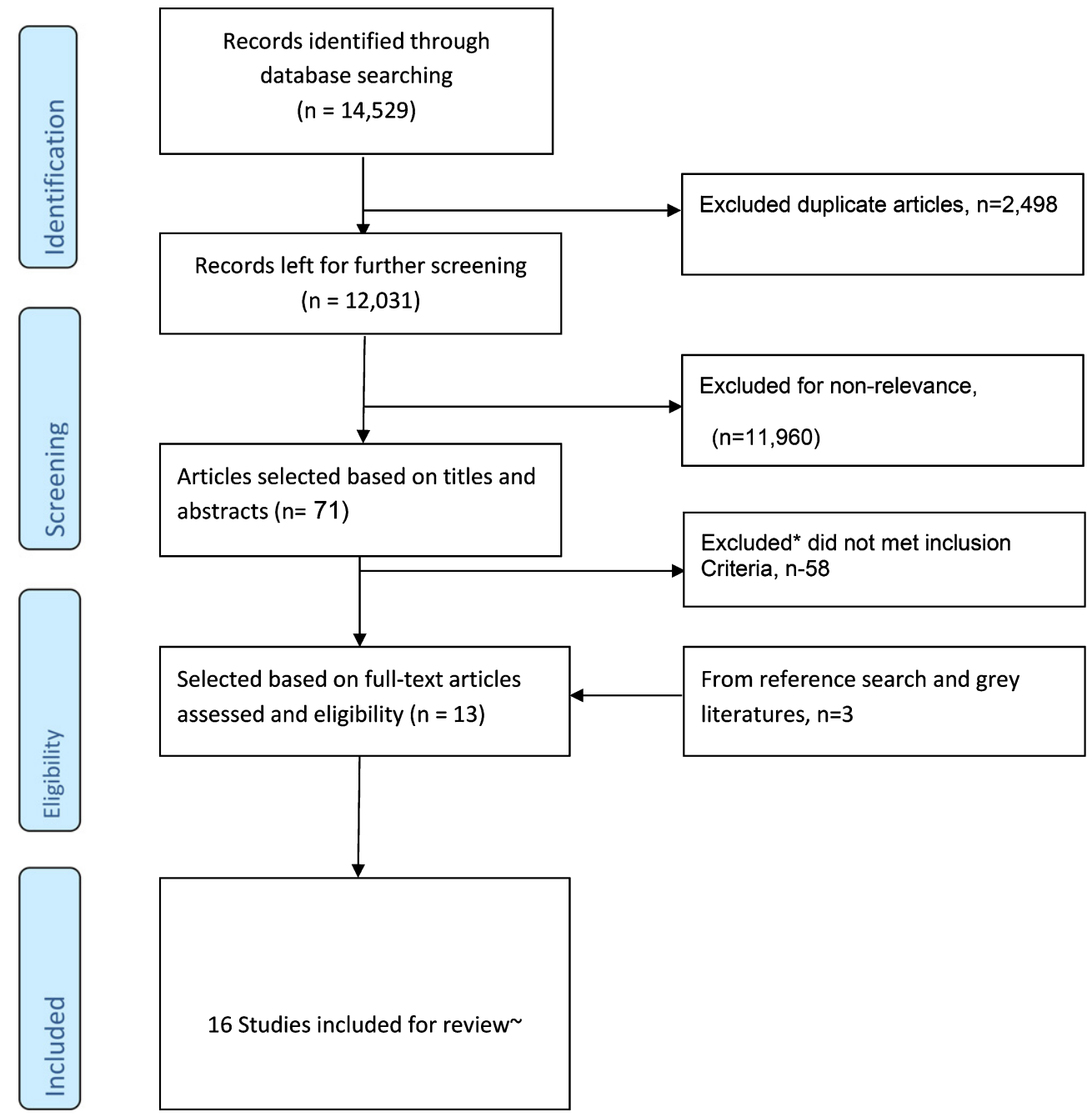

Fig. 1. Flowchart for literature search, selection, and inclusion of studies for the research. * Reasons included: studied midlife or younger baseline age $<65$ years, other outcome variables such as MCI, dementia+MCI, did not assess the key predictor (BMI or WC), different study design (such as cross-sectional or case control), etc. $\sim$ Two studies were not used for meta-analysis due to fewer adjustments for co-variates.

and 95\% CIs from confounder adjusted models were considered for this analysis. RR was estimated using a random effect model provided there was a statistically significant heterogeneity test, indicative of differences among included studies, or else a fixed effect model was used. We used a funnel plot to assess the risk of publication bias.

First, we took all RRs from the studies with continuous BMI data or the highest BMI category if the studies did not examine continuous BMI data for use in the meta-analysis to give an overall picture for the association between increased BMI and incident dementia. Then, we pooled continuous data and categorical BMI (obese, overweight, normal, and underweight people; reference categories were those used in the respective primary studies) separately. We stratified the analysis by duration of study follow-up as this could help minimize the reverse effects on the association between overweight/obesity and dementia. We considered that a cut-off year of 9 for the follow up (i.e., short term $<9$ years and long term $\geq 9$ years) in such subgroup meta-analysis was adequate to observe the consequence of overweight and obesity. This is because the average length of followup required to observe incident dementia since being exposed to a risk factor in older age, including the prodromal phase of the disease, ranges from 7-8 years [20], and in the middle-aged population studies is longer (e.g., 10 years) [21, 22]. Based on these, it would be appropriate to use the cut-off point of 9 
years for the subgroup data analysis to minimise reverse association between dementia and adiposity in older age. It would be likely that the duration of follow up would account for or contribute to the differences in findings from cohort studies [23].

In the meta-analysis of the impact of WC on incident dementia, we defined WC third quartile or the next above the normal/no action level as large WC and the highest group as larger WC based on existing literature. We then pooled available data for the large WC and larger WC group from identified study populations and the new unpublished Chinese study [19]. All analyses were done using the Stata/IC 14.0 statistical software package.

\section{RESULTS}

\section{Literature review}

Out of 16 cohort studies identified for review, seven were undertaken in the USA, two in Finland, two in Sweden, and one each in Denmark, France, Italy, Australia, and Japan, all being from high income countries. Sample sizes ranged from 226 to 12,047 and in total included 41,781 participants and 4,511 dementia cases. The duration of follow up in these cohorts varied from 3 to 18 years. Of 16 studies, 12 investigated all types of dementia in relation to adiposity [24-35], among which eight further examined the association of AD with BMI $[7,12,13$, 36-40] while six analyzed the data for $\mathrm{AD}$ and $\mathrm{VaD}$ separately [32, 33, 35, 41-43]. In four studies which did not examine data from all types of dementia, three focused on AD only [44-46] and one investigated $\mathrm{AD}$ and $\mathrm{VaD}$ separately [47]. In all, there were 12 studies on BMI and AD and seven on BMI and VaD.

Among these published studies, thirteen $[7,12,13$, $36,38-40,44,46-50]$ used calculated BMI from measured weights and heights, while three other papers $[11,37,51]$ used participant's self-reported BMI. Eleven studies used continuous BMI for analysis, four of which also examined the categorized BMI, and three studies used the categorized BMI for analysis only (study of overweight and obesity in relation to dementia. Three studies [38, 40, 48] used both BMI and WC for analysis and one investigated BMI and Waist-To-Hip [7]. Only four studies [37, 39, 44, 49] could present their findings for BMI and dementia (or AD) with stratification by sex, and three others examined a single gender (female sample $[13,36]$ or a male sample [48]). Two studies [38, 49] presented results as per age group of older people (e.g., younger 65-76 years or older $\geq 76$ years), and one study stratified results according to APOE $\varepsilon 4$ carriers and noncarriers status [39]. Of sixteen studies, seven [37, 39, $44,47,50,51]$ did not adjust for smoking and medical co-morbidities in their data analysis, but one of them excluded non-smokers but did not adjust for medical comorbidities [38] and other adjusted for medical co-morbidities but not smoking [50]. The details of the methods and characteristics of these studies are shown in Supplementary Table 1. Based on the Newcastle Ottawa assessment scale, we rated their study qualities on good to excellent levels (Table 1).

There were thirteen studies showing an inverse association of BMI with dementia [28-31, 33-35, $42,46,47,50,52,53]$, of which ten were statistically significant [7, 11-13, 38, 39, 46, 48-50]. In contrast, only two studies $[36,37]$ suggested a significant and positive prediction of BMI to dementia, while one showed a non-significant increased risk of dementia [44]. In three studies which analyzed WC for central fat, one found a significant association between 'large WC' and increased risk of AD but not all types of dementia [38] and the other two [32-34] did not show any significant impact of large WC on incident dementia.

The data from our new unpublished Chinese study [19] demonstrates that older men who had overweight and obesity had increased risk of incident dementia, but women with overweight and obesity may have a non-significant reduction of incident dementia.

\section{Meta-analysis}

In the above 16 published articles that we reviewed (Table 1), we excluded two studies [47, 51] from the meta-analysis as the authors did not adjust for enough confounders to calculate the RR of dementia in relation to overweight and obesity. We added in the data from the new Chinese study for the metaanalysis. Thus, there were 15 studies (including 17 studied populations) left for pooled data analysis, comprising of 37,369 participants and 4,189 dementia cases (Fig. 2). Pooling data of the RR of dementia in relation to continuous BMI (or obesity if the continuous BMI data was not available) (Fig. 2) showed a non-significant reduced risk of dementia, with a relative risk of 0.97 (95\% CI 0.94-1.00), $p=0.055$. After excluding those three studies [11,37, 51] which used participants' self-reported BMI, we found that the significance for the association was reduced (RR $0.97,0.94-1.00, p=0.065)$. The analysis of all 17 studied populations did not show evidence of publi- 
Table 1

Quality assessment of cohort studies on obesity and dementia risk

\begin{tabular}{|c|c|c|c|c|c|c|c|c|c|c|}
\hline Study & 1 & 2 & 3 & 4 & 5 & 6 & 7 & 8 & 9 & 10 \\
\hline Yoshitake et al. [47] & $\star$ & $\star$ & $\star$ & $\star$ & $\star$ & & & $\star$ & $\star$ & $\star \star$ \\
\hline Borenstein et al. [44] & $\star$ & $\star$ & $\star$ & $\star$ & $\star$ & & $\star$ & $\star$ & $\star$ & $\star$ \\
\hline Gustafson et al. [43] & $\star$ & $\star$ & $\star$ & $\star$ & $\star$ & $\star$ & $\star$ & $\star$ & $\star$ & $\star$ \\
\hline Nourhashemi et al. [29] & $\star$ & $\star$ & & $\star$ & $\star$ & & $\star$ & & & \\
\hline Buchman et al. [50] & $\star$ & $\star$ & $\star$ & $\star$ & $\star$ & & $\star$ & $\star$ & $\star$ & $\star$ \\
\hline Hayden et al. [41] & $\star$ & $\star$ & & $\star$ & $\star$ & & $\star$ & $\star$ & $\star$ & $\star$ \\
\hline Lunchsinger et al. [33] & $\star$ & $\star$ & $\star$ & $\star$ & $\star$ & & $\star$ & $\star$ & $\star$ & $\star$ \\
\hline Atti et al. [30] & $\star$ & $\star$ & $\star$ & $\star$ & $\star$ & & $\star$ & $\star$ & $\star$ & $\star$ \\
\hline Dahl et al. [31] & $\star$ & $\star$ & $\star$ & $\star$ & $\star$ & $\star$ & $\star$ & $\star$ & $\star$ & $\star$ \\
\hline Hughes et al. [32] & $\star$ & $\star$ & $\star$ & $\star$ & $\star$ & $\star$ & $\star$ & $\star$ & $\star$ & $\star$ \\
\hline Fitzpatrick et al. [35] & $\star$ & $\star$ & $\star$ & $\star$ & & $\star$ & $\star$ & $\star$ & $\star$ & $\star$ \\
\hline Scarmeas et al. [46] & $\star$ & $\star$ & $\star$ & $\star$ & $\star$ & $\star$ & $\star$ & $\star$ & $\star$ & $\star$ \\
\hline Power et al. [34] & $\star$ & $\star$ & $\star$ & $\star$ & & $\star$ & $\star$ & $\star$ & $\star$ & $\star$ \\
\hline Lucca et al. [28] & $\star$ & $\star$ & & $\star$ & $\star$ & $\star$ & $\star$ & $\star$ & & \\
\hline Tolppanen et al. [52] & $\star$ & $\star$ & $\star$ & $\star$ & $\star$ & $\star$ & $\star$ & $\star$ & & $\star$ \\
\hline Neergaard et al. [42] & $\star$ & $\star$ & $\star$ & $\star$ & & $\star$ & $\star$ & $\star$ & $\star$ & $\star$ \\
\hline
\end{tabular}

(1) Cohort truly representative; (2) Controls from the same cohort; (3) Clear measurement of obesity at baseline; (4) Adequacy of Follow-up duration ( $\geq 24$ months); (5) Reliable methods of dementia and AD diagnosis (i.e., Quality of outcome); (6) Data analysis controlled for smoking and medical co-morbidities; (7) Data analysis controlled for any other three confounders (Age, social class/education, alcohol, ApoE4 carrier status, medical therapies and ethnicity etc.); (8) Findings interpreted well; (9) Weakness mentioned and explained clearly; (10) Paper written well.

cation bias (funnel plot in Supplementary Figure 1), with Egger's test $p=0.564$.

Using data from all 17 studied populations (Fig. 2), a further analysis stratified by duration of study follow-up showed that the RR of dementia was 0.95 (0.92-0.97) for short term follow-up ( $<9$ years) and $1.00(0.93-1.08)$ for long term follow up ( $\geq 9$ years) (Supplementary Figure 2). On examining the data of $\mathrm{AD}$ as outcome only (Supplementary Figure 3), the matched figures were $0.93(0.88-0.99)$ and 0.99 (0.70-1.39), respectively, while the overall RR for $\mathrm{AD}$ in relation to adiposity from all available studies (Supplementary Figure 4) was 0.95 (0.89-1.02). In those 14 studied populations with continuous BMI data analysis in the top part of Fig. 2 (16,576 participants with 2,372 dementia cases), the RRs for dementia in the short-term and long-term followup years studies were $0.95(0.93-0.96)$ and 1.03 (0.96-1.11), respectively (Fig. 3).

Table 2 shows the findings from the different categorized BMI analyses in five studies (including the new Chinese study). Compared to normal BMI, older people with overweight and obesity exhibited a non-significant reduced risk of dementia; the RR of dementia was $0.87(0.66-1.14)$ and 0.86 (0.60-1.22), respectively. Compared to combined normal and underweight BMI categories, the matched RRs remained non-significant; in overweight 0.98 (0.54-1.77) and in obesity 1.17 (0.65-2.10) (Table 2). Further and separate analysis of $\mathrm{AD}$ showed no association for continuous BMI nor for obesity (Supplementary Figure 5). However, the risk of AD was reduced for overweight $(0.69,0.57-0.88)$ while no association was observed for $\mathrm{VaD}$ in relation to obesity (0.91, 0.60-1.39) (Supplementary Figure 6).

The findings of the analysis of large WC and dementia risk showed non-significant changes in risk for those with large WC (RR: 1.04, 0.90-1.20) and larger WC (RR: 0.94, 0.80-1.09) (Fig. 4).

\section{DISCUSSION}

In this paper, we carried out a comprehensive systematic review and meta-analysis, which included new data from China. The pooled data from cohort studies with $<9$ years follow up showed a significantly reduced dementia risk in relation to obesity and overweight in older age, but studies with longer follow-up reported no association of overweight and obesity in older age with incident dementia, including AD.

\section{Strength and limitations}

This study, to the best of our knowledge, is the first systematic review and meta-analysis that comprehensively explored dementia risk in relation to obesity and overweight, assessed by different anthropometric measures, in strictly older adults' population and examined differences in the impact of follow-up 


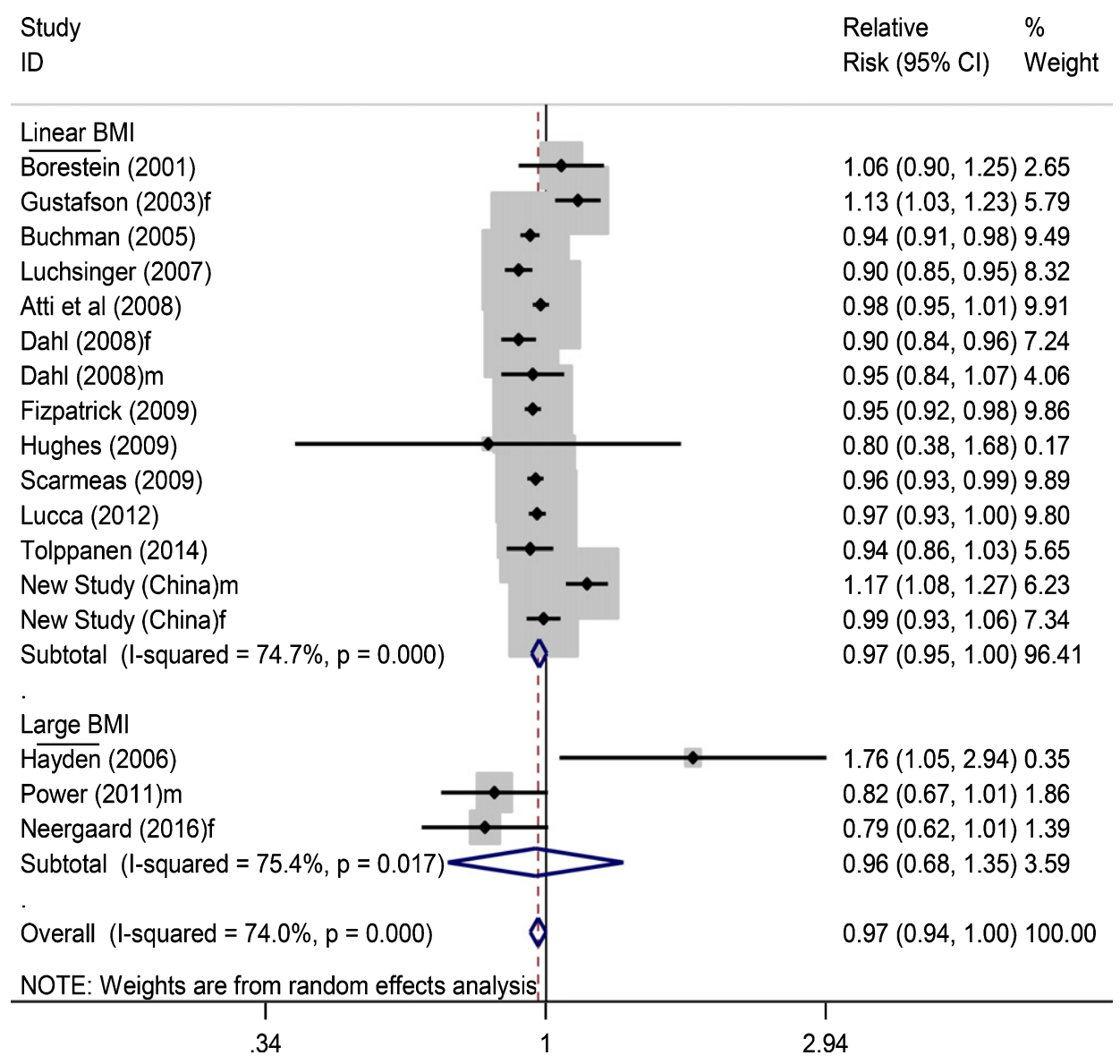

Fig. 2. Forest plot showing pooled estimates of all included studies for BMI and dementia risk. Three studies, i.e., in low part of the figure, did not examine the association of continuous BMI and dementia, and thus the overall meta-analysis took their data of categorized BMI in the highest group. f, female; $\mathrm{m}$, male.

Table 2

Risk of incident dementia in relation to categorized BMI group analysis in pooling data

\begin{tabular}{|c|c|c|c|c|}
\hline $\begin{array}{l}\text { BMI variable } \\
\text { (study reference) }\end{array}$ & $\begin{array}{l}\text { Number of } \\
\text { studied } \\
\text { population }\end{array}$ & $\begin{array}{l}\text { Number of } \\
\text { participants }\end{array}$ & $\begin{array}{c}\text { Number of } \\
\text { dementia } \\
\text { Number of cases }\end{array}$ & $\mathrm{RR}(95 \% \mathrm{CI})$ \\
\hline \multicolumn{5}{|l|}{ Categorized BMI analysis (I) } \\
\hline Overweight $[28,30,42,76]^{\mathrm{a}}$ & 6 & 11,864 & 1,568 & $0.87(0.66-1.14)$ \\
\hline Obesity $[28,30,42,76]^{\mathrm{a}}$ & 5 & 11,644 & 1,585 & $0.86(0.60-1.22)$ \\
\hline Underweight $[28,30,42,76]^{\mathrm{a}}$ & 5 & 12,899 & 1,882 & $0.92(0.64-1.33)$ \\
\hline \multicolumn{5}{|l|}{ Categorized BMI analysis (II) } \\
\hline Overweight $[34,52]$ & 4 & 15,608 & 1,453 & $0.98(0.54-1.77)$ \\
\hline Obesity $[34,41,52]^{*}$ & 5 & 18,872 & 1,594 & $1.17(0.65-2.10)$ \\
\hline
\end{tabular}

duration on the relationship. It also examined the effects of WC on incident dementia and differences in the impact of adiposity on $\mathrm{AD}$ and $\mathrm{VaD}$, which were absent from previous reviews in older people. We included data of 41,781 participants from
16 published studies and added-in the unpublished new study data from China to assess dementia risk in relation to older age overweight and obesity, and the findings of our study are robust. Our study has limitations. First, we could not perform a sex-stratified 


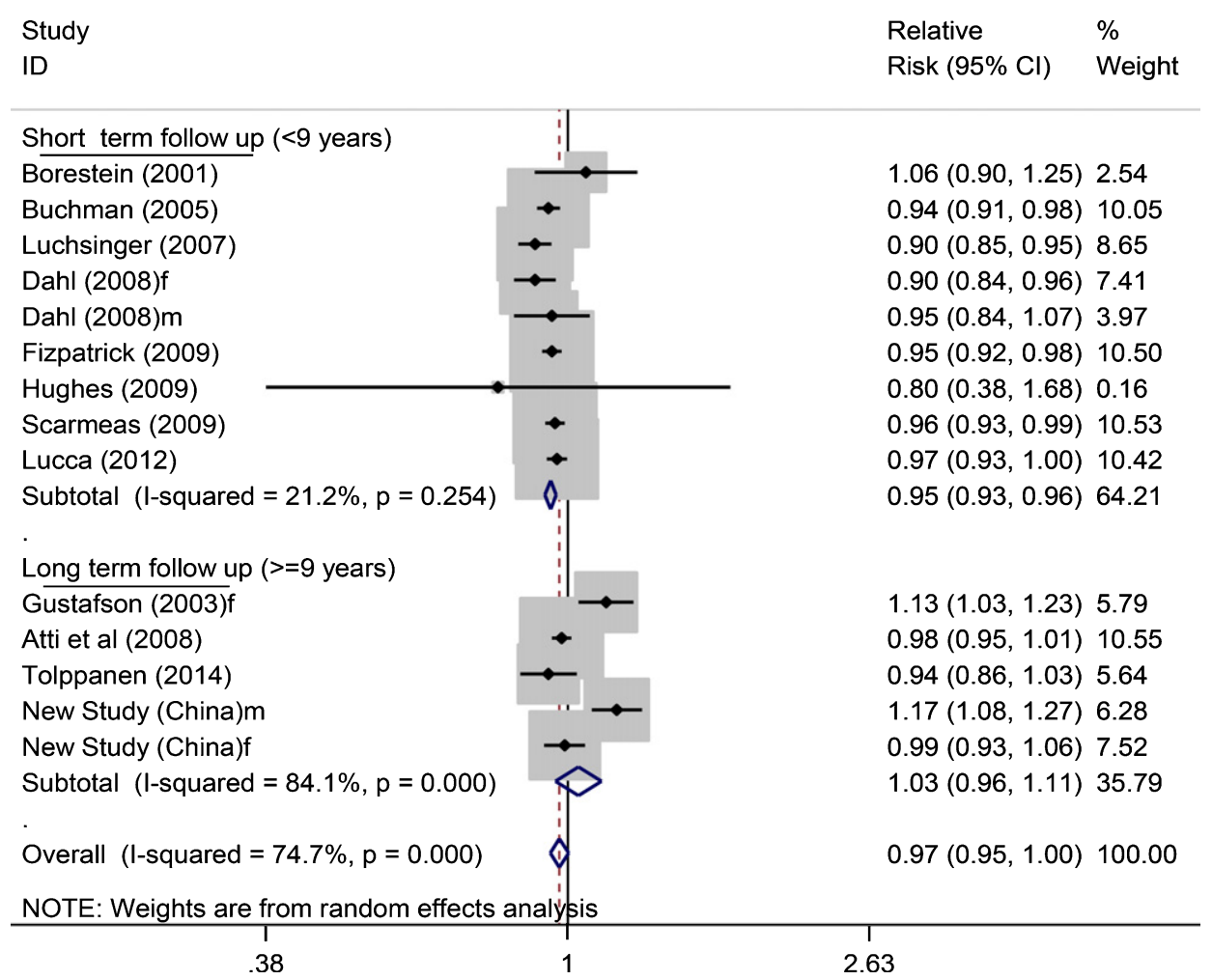

Fig. 3. Continuous BMI and dementia risk (short term versus long term follow up). In total, 11,376 participants with 1,741 dementia cases for short term and in total 5,198 participants with 631 dementia cases for long term studies. f, female; m, male.

analysis to examine any gender differences within the impact of overweight/obesity on the incident dementia risk equation, while our new study from China showed gender differences in the impact. This is due to the limited number of primary studies that reported separate findings for males and females. The gender differences in the impact of overweight and obesity needs to be further investigated in future research. Second, although we tried to compare the impact of adiposity in older age on $\mathrm{AD}$ and $\mathrm{VaD}$ since the pooled data showed possible increase in the risk of $\mathrm{VaD}$ and reduction of $\mathrm{AD}$ in relation to adiposity, we could not find significant differences between them. This is partially due to a small number of studies that examined $\mathrm{AD}$ and $\mathrm{VaD}$ separately. Future original studies should be encouraged to add in data analysis for $\mathrm{AD}$ and $\mathrm{VaD}$ respectively, which would contribute to identifying their differences in the impact. Third, we could not compare the impacts of overweight and obesity on incident dementia between high and low/middle income countries as only few studies have been undertaken in these latter countries. This highlights the need for more prospective cohort studies from low and middle-income countries.
Our review showed that while most studies reported the inverse association between excess weight and incident dementia, there were notable differences among studies and their findings which may be explained by age at obesity assessment, length of follow-up, type adiposity measure, adjustments for confounders, pre-existing illness and reverse causation, gender effect, and dementia types.

\section{Age at adiposity assessment}

The review of evidence from a decade of research of BMI and dementia risk (2003-2013) suggest that the impacts of overweight and obesity on incident dementia are varied according to the age at which they were assessed [54]. Indeed, recent findings from studies in younger and middle age populations $(\leq 65$ years) have demonstrated that excessive body weights increased the risk of incident dementia [4], while the contrary has been the case for most reported findings of overweight and obesity assessed in older age $[5,6]$. The analysis of combined data for obesity $\left(\mathrm{BMI}>40 \mathrm{Kg} / \mathrm{m}^{2}\right)$ measured in both younger and older age (mean age 55 years) may produce find- 


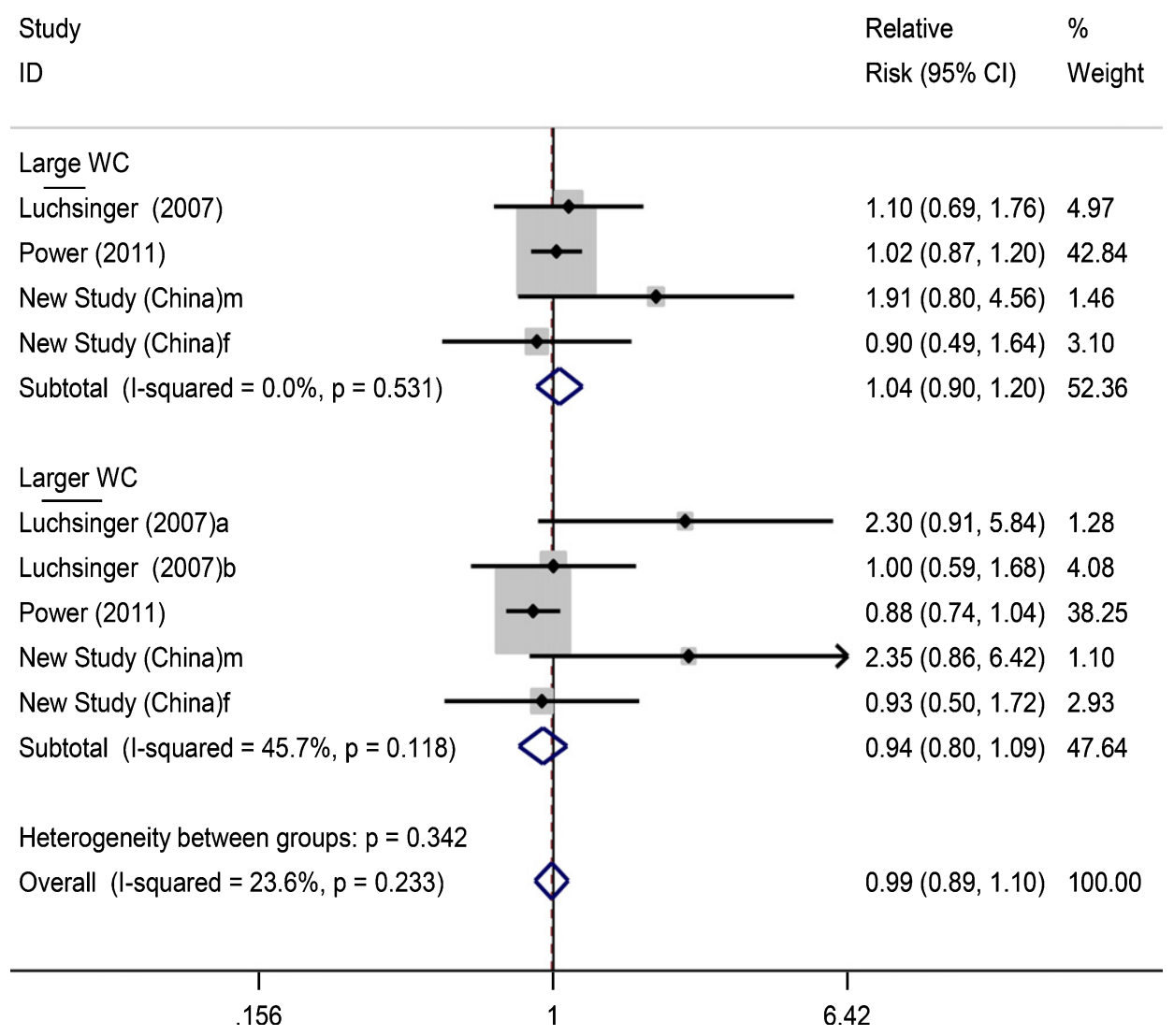

Fig. 4. Forest plots for large and larger waist circumference and dementia risk. f, female; m, male.

ings of a significant reduced dementia risk of $29 \%$ as reported by Qizilbash et al. in the UK [9]. However, it is difficult to separate the specific effect for older people from data that included younger age groups. The findings of inverse associations observed in similar studies of BMI and dementia risk may be limited by shorter follow-up of the study [55, 56]. There is also potential bias from possible weight loss encountered prior to the onset of dementia [56]. While the majority of older age BMI and dementia studies which were included in our study reported inverse associations, the meta-analysis stratified by length of follow up demonstrated that this is only true in studies with short term follow-up ( $<9$ years).

\section{Length of follow-up}

The harmful consequences of overweight and obesity in older people may take time to manifest, even though the survival hypothesis suggests that there may be a sub-population that could be resistant to or survive the effects [55]. Our findings from the meta-analysis have confirmed that the harmful consequences of overweight and obesity in older age on dementia risk is hard to observe in short-term follow-up cohort studies, whereas the inverse association could be found due to possible reverse causation. A recent study by Kivimaki et al. who examined unpublished individual-participant data based on health records (1.3 million people from Europe, USA, and Asia general populations with mean age of 36.3-55.2 years at baseline BMI assessment showed evidence that the harmful effect of higher BMI on dementia risk was from studies with long term but not short-term follow-up [56]. Our meta-analysis results have suggested that this may also be true in older age using data from prospective cohort studies with long term follow-up. It also implies that perhaps obesityyears may be more important in predicting future dementia risk. Notably in our systematic review, two studies [36, 37], of which one had long duration of follow up [36], found increased dementia risk for excess body weights. The previous study by Gustafson et al, with the longest duration of followup (18 years) showed that women who developed dementia between 79 and 88 years had higher BMI 
at the age of 70 years compared to those that did not develop dementia. Findings from the new Chinese study also demonstrated the harmful consequences of overweight and obesity on increased dementia in men over 10 years follow-up regardless of the measure of adiposity that was used.

\section{Type of adiposity measure}

The literature on obesity and aging suggests that body fat percentage is known to be raised with aging and so is higher accumulation of intra-abdominal fats due to body fat redistribution [55, 57]. The central intra-abdominal fat is a significant risk factor for cardiovascular diseases [58-60]. Despite this, epidemiological studies have explored overweight and obesity more frequently using BMI than WC which is considered as a better indicator of abdominal adiposity. Our review showed that among the 16 published studies for review only three investigated the impacts of large WC on dementia risk. While most of the included studies [32-34] in our review reported no association of WC with dementia, the study by Luchsinger et al. [33] found that there was more than a five-fold increase in the risk of $\mathrm{AD}$ in relation to adiposity, although no significant association with all types of dementia was found. The evidence from the new unpublished Chinese study showed a nonsignificant increase in dementia risk in older people with WC 85-95 cm (1.91, 95\%CI: 0.80-4.56) and WC $>95 \mathrm{~cm}(2.35,95 \% \mathrm{CI}: 0.86-6.42)$ in men and no association in women.

\section{Adjustments for confounders}

There is strong evidence for the association of dementia with smoking and comorbidities such as stroke and diabetes [61-64]. In addition, older people with positive Apolipoprotein E- $\varepsilon 4$ status, which is also related to obesity, are likely to develop late life dementia [65]. The lack of adjustments for these factors may bias the findings from those prospective cohort studies. Surprisingly, out of the 16 published studies, seven studies did not adjust for confounding factors of smoking and/or comorbidities in their statistical analysis [37, 38, 39, 44, 47, 50, 51]. We observed that despite most studies considering these important confounders, the reports of inverse associations still dominated the literature on older people. This may be due to less attention on the effects of reverse causation which could disguise the actual results. The complexity surrounding age related co-morbidities and the possible effects on body weights and subsequent dementia risk suggest that the influence of pre-existing illness from primary researchers requires more scrutiny.

\section{Pre-existing illness}

One challenge for the study of obesity and dementia risk is dealing with the possible risk of bias emanating from pre-existing illness in the elderly. Older people, particularly those with chronic illness, may lose weight and become prone to dementia. Yet it is obviously difficult to discount pre-existing illness in old age even with tighter baseline assessments of the health status of participants. The extent to which this may confound results of observational studies has been debated [55].

\section{Reverse causation}

Evidence showed that weight loss may occur in older adults up to 10 years before dementia diagnosis [66]. Although the causes or mechanisms of weight loss in older adults remain unclear, reverse causation may emanate from weight loss due to obesity-related or unrelated illness that may impact on appetite and nutrition including dementia [67]. A recent study by Kivimaki et al. suggested that the effects of BMI on dementia risk are ascribed to both a direct causal link and reverse causation [56]. This highlights the need to account for reverse causation in observational studies. However, only few studies considered reverse causation, and the issue, of which approach is preferred, remains debatable. In our identified articles for systematic review, only five studies [38, $39,48,49,51]$ attempted such a sensitivity analysis. Even when they did so, in some studies [39, 51] it did not appear to be related to minimization of any bias that might arise from pre-existing illness and reverse causality. For instance, the Swedish longitudinal research [39] found an inverse relationship between higher BMI (overweight/obesity) and reduced risk of dementia after 9 years follow-up (HR: 0.75 , 95\% CI: 0.59-0.96); but after sensitivity analysis that excluded first 3 years cases, the significant association vanished (HR: 0.66, 95\% CI: 0.40-1.07), probably due to reduced number of dementia cases. Nevertheless, the study interpreted and concluded that higher BMI $\left(\geq 25 \mathrm{Kg} / \mathrm{m}^{2}\right)$ may be protective and reflective of good health. Thus, there is need to examine sensitivity analyses to determine if the inverse association of dementia and excess body weights are 
true effects or are instead influenced by reverse causation.

\section{Gender effect}

Recent data of gender-specific associations between increased lipids and cognitive decline revealed disparities in the risk of cognitive impairment for men and women [68]. Despite the importance, there is less focus on gender in obesity and dementia research. Our review showed that most studies did not consider gender differences in the impact of overweight and obesity on incident dementia in their analysis. In fact, there were only four published studies that did so [37, 39, 44, 49], while three others focused only on either male or female. The study by Hayden et al. [25], which presented stratified results by gender but was restricted to the dementia subtypes ( $\mathrm{AD}$ and $\mathrm{VaD}$ ), showed an increased risk for $\mathrm{AD}$ in women with obesity (HR 2.23, 1.09-4.30) but no significant increase in incident $\mathrm{AD}$ in men (1.48, 0.41-4.18), although no association was noticed for $\mathrm{VaD}$. Interestingly, the new cohort study from China demonstrated over 10 years of follow-up and using different adiposity measures (BMI, WC, and $\mathrm{WC} / \sqrt{ }$ height) that overweight and obesity in older adults increased dementia risk in men but not women. Considering these findings, and limited research, more studies are needed to examine gender effect on the association of overweight or obesity with dementia risk in older people.

\section{Dementia types}

The etiology of dementia is complex and different types of dementia may have different risk factors. We tried to examine differences in the impact of adiposity on $\mathrm{AD}$ and $\mathrm{VaD}$ based on the theory that metabolic factors are important for $\mathrm{VaD}$ where vascular etiology is involved, but may not be important for pure $\mathrm{AD}$ [69-71]. Although clinically dementia types cannot be accurately discerned, the findings from published study [69] suggest that the association with adiposity may vary among $\mathrm{AD}$ and $\mathrm{VaD}$. While metabolic factors may be more important in the etiology of VaD $[69,71]$, the genes, e.g., APOE and TOMM40, increase susceptibility to $\mathrm{AD}[72,73]$. Our metaanalysis stratified by dementia subtypes in relation to linear/large BMI from all available data (Supplementary Figure 3) showed a relative risk of 0.95 (0.89-1.02) for AD (11 studies) and 1.03 (0.93-1.14) for $\mathrm{VaD}$ (six studies), respectively. There were no differences between the two RRs; the ratio of RRs was $0.92(0.82-1.04), p=0.196$. The differences were not significant, maybe due to the small number of studies examining the association of dementia types with adiposity in older people. However, we have noted in the data analysis that the inverse association of $\mathrm{AD}$ with $\mathrm{BMI}$ was from those short-term follow-up studies only, but not from the long-term follow-up outcomes (Supplementary Figure 3). This may suggest that the inverse association of $\mathrm{AD}$ with adiposity in older people is untrue. Previous studies in younger aged populations ( $<60$ years old) showed that the risk of AD was increased in overweight $(1.35,1.19-1.54)$ and obesity $(2.04,1.59-2.62)$ [74]. A previous metaanalysis study [75], including older and younger aged populations (baseline age $\geq 40$ years) also found that obesity significantly increased the risk of $\mathrm{AD}$ (1.80, 1.00-3.29). In our meta-analysis of older age adiposity studies, if there were no association of AD with overweight and obesity, there would not be significant differences in the impact of adiposity on $\mathrm{AD}$ and $\mathrm{VaD}$.

\section{Implications and conclusions}

Our systematic review and meta-analysis have several implications for policy making and public health practice. The findings suggest that obesity and overweight in older people is not protective against dementia risk. There is insufficient evidence to support recommendation of weight loss in older adults for the purpose of reducing dementia risk directly. However, it is likely that there are indirect effects of overweight and obesity in older age on dementia via other chronic conditions, e.g., diabetes, since these chronic conditions in older age are related to incident dementia. Thus, controlling bodyweight, even in older age, may prevent incident dementia. There is a lack of data from Asia on this topic, where the bodyweight is lower than those in Europe and northern America, including in the older population. Consequently, it is important to know if the trends of the impact of overweight and obesity in older adults on incident dementia are similar between Asian and European or US populations. It is possible that BMI thresholds at which risk commences differs by gender, ethnicity, and race. These need further research. Nevertheless, maintaining normal body weight from young to older ages as recommended by the current guidelines is necessary, and public health prevention and intervention strategies for tackling overweight and obesity should be sustained in older people. 


\section{ACKNOWLEDGMENTS}

Professor Ruoling Chen thanks European Commission Horizon 2020 Framework Programme for an MSCA grant (DEMAIRPO), and the BUPA Foundation and Alzheimer's Research UK grants to support research on dementia epidemiology and care.

Authors' disclosures available online (https:// www.j-alz.com/manuscript-disclosures/18-0763r1).

\section{SUPPLEMENTARY MATERIAL}

The supplementary material is available in the electronic version of this article: http://dx.doi.org/ 10.3233/JAD-180763

\section{REFERENCES}

[1] Prince M, Wino A, Guerchet M, Ali G, Wu Y, Prina M (2016) World Alzheimer Report 2015. The Global Impact of Dementia: An analysis of prevalence, incidence, cost and trends. Alzheimer's Disease International, London, UK.

[2] Alzheimer's Association (2016) 2016 Alzheimer's disease facts and figures. Alzheimers Dement 12, 459-509.

[3] Anstey KJ, Cherbuin N, Budge M, Young J (2011) Body mass index in midlife and late-life as a risk factor for dementia: A meta-analysis of prospective studies. Obes Rev 12, e426-e437.

[4] Albanese E, Launer LJ, Egger M, Prince MJ, Giannakopoulos P, Wolters FJ, Egan K (2017) Body mass index in midlife and dementia: Systematic review and meta-regression analysis of 589,649 men and women followed in longitudinal studies. Alzheimers Dement (Amst) 8, 165-178.

[5] Wotton CJ, Goldacre MJ (2014) Age at obesity and association with subsequent dementia: Record linkage study. Postgrad Med J 90, 547-551.

[6] Pedditizi E, Peters R, Beckett N (2016) The risk of overweight/obesity in mid-life and late life for the development of dementia: A systematic review and meta-analysis of longitudinal studies. Age Ageing 45, 14-21.

[7] Fitzpatrick AL, Kuller LH, Lopez OL, Diehr P, O’Meara ES, Longstreth W, Luchsinger JA (2009) Midlife and latelife obesity and the risk of dementia: Cardiovascular health study. Arch Neurol 66, 336-342.

[8] Beydoun MA, Beydoun H, Wang Y (2008) Obesity and central obesity as risk factors for incident dementia and its subtypes: A systematic review and meta-analysis. Obes Rev 9, 204-218.

[9] Qizilbash N, Gregson J, Johnson ME, Pearce N, Douglas I, Wing K, Evans SJ, Pocock SJ (2015) BMI and risk of dementia in two million people over two decades: A retrospective cohort study. Lancet Diabetes Endocrinol 3, 431-436.

[10] Wang Z, Liu M, Pan T, Tong S (2016) Lower mortality associated with overweight in the U.S. National Health Interview Survey: Is overweight protective? Medicine (Baltimore) 95 , e2424.

[11] Lucca U, Tettamanti M, Garrí M, Riva E, Nobili A, Pasina L, Franchi C, Djade C, Recchia A (2012) Body mass index and dementia in the oldest-old: The Monzino 80-Plus Study. Alzheimers Dement 8, P326.
[12] Tolppanen A, Ngandu T, Kåreholt I, Laatikainen T, Rusanen M, Soininen H, Kivipelto M (2014) Midlife and late-life body mass index and late-life dementia: Results from a prospective population-based cohort. J Alzheimers Dis 38, 201-209.

[13] Neergaard JS, Dragsbaek K, Hansen HB, Henriksen K, Christiansen C, Karsdal MA (2016) Late-Life risk factors for all-cause dementia and differential dementia diagnoses in women: A prospective cohort study. Medicine (Baltimore) 95, e3112.

[14] Khan KS, Kunz R, Kleijnen J, Antes G (2003) Five steps to conducting a systematic review. J R Soc Med 96, 118-121.

[15] Bettany-Saltikov J (2012) How to do a Systematic Literature Review in Nursing: A Step-by-Step Guide, McGraw-Hill Education (UK).

[16] Lucca U, Tettamanti M, Logroscino G, Tiraboschi P, Landi C, Sacco L, Garrí M, Ammesso S, Bertinotti C, Biotti A (2015) Prevalence of dementia in the oldest old: The Monzino 80-plus population based study. Alzheimers Dement 11, 258-270.e3.

[17] Liberati A, Altman DG, Tetzlaff J, Mulrow C, Gøtzsche PC, Ioannidis JP, Clarke M, Devereaux PJ, Kleijnen J, Moher D (2009) The PRISMA statement for reporting systematic reviews and meta-analyses of studies that evaluate health care interventions: Explanation and elaboration. PLoS Med 6, e1000100.

[18] Wells GA, Shea B, O'Connell D, Peterson J, Welch V, Losos M, Tugwell P. The Newcastle-Ottawa Scale (NOS) for assessing the quality of nonrandomised studies in metaanalyses. Available from: http://www.ohri.ca/programs/cli nical_epidemiology/oxford.asp.

[19] Danat IM, Chen R (2018) Do older adults obesity and overweight prevent dementia risk? - A new population-based cohort study from China. Alzheimer's Disease, Dementia Care Research and Awarenes Conference. Boston, Massachusetts, USA. August 31-September 01, 2018 [https://alzheimers.global-summit.com/scientificprogram].

[20] Johnson DK, Wilkins CH, Morris JC (2006) Accelerated weight loss may precede diagnosis in Alzheimer disease. Arch Neurol 63, 1312-1317.

[21] Knopman DS, Edland SD, Cha RH, Petersen RC, Rocca WA (2007) Incident dementia in women is preceded by weight loss by at least a decade. Neurology 69, 739-746.

[22] Kivimäki M, Luukkonen R, Batty GD, Ferrie JE, Pentti J, Nyberg ST, Shipley MJ, Alfredsson L, Fransson EI, Goldberg M, Knutsson A, Koskenvuo M, Kuosma E, Nordin M, Suominen SB, Theorell T, Vuoksimaa E, Westerholm P, Westerlund H, Zins M, Kivipelto M, Vahtera J, Kaprio J, Singh-Manoux A, Jokela M (2017) Body mass index and risk of dementia: Analysis of individual-level data from 1.3 million individuals. Alzheimers Dement 14, 601-609.

[23] Gustafson DR, Backman K, Waern M, Ostling S, Guo X, Zandi P, Mielke MM, Bengtsson C, Skoog I (2009) Adiposity indicators and dementia over 32 years in Sweden. Neurology 73, 1559-1566.

[24] Gustafson D, Rothenberg E, Blennow K, Steen B, Skoog I (2003) An 18-year follow-up of overweight and risk of Alzheimer disease. Arch Intern Med 163, 1524-1528.

[25] Hayden KM, Zandi PP, Lyketsos CG, Khachaturian AS, Bastian LA, Charoonruk G, Tschanz JT, Norton MC, Pieper CF, Munger RG, Breitner JC, Welsh-Bohmer KA, Cache County Investigators (2006) Vascular risk factors for incident Alzheimer disease and vascular dementia: The Cache County study. Alzheimer Dis Assoc Disord 20, 93-100. 
[26] Neergaard JS, Dragsbaek K, Hansen HB, Henriksen K, Christiansen C, Karsdal MA (2016) Late-life risk factors for all-cause dementia and differential dementia diagnoses in women: A prospective cohort study. Medicine (Baltimore) 95, e3112.

[27] Tolppanen A, Ngandu T, Kåreholt I, Laatikainen T, Rusanen M, Soininen H, Kivipelto M (2014) Midlife and late-life body mass index and late-life dementia: Results from a prospective population-based cohort. J Alzheimers Dis 38, 201-209.

[28] Lucca U, Tettamanti M, Garri M, Riva E, Nobili A, Pasina L, Franchi C, Djade C, Recchia A (2012) Body mass index and dementia in the oldest-old: The Monzino 80-Plus Study. Alzheimers Dement 8(4 Suppl), P326.

[29] Nourhashémi F, Deschamps V, Larrieu S, Letenneur L, Dartigues J-, Barberger-Gateau P, PAQUID study Personnes Agées Quid (2003) Body mass index and incidence of dementia: The PAQUID study. Neurology 60, 117-119.

[30] Atti A (2008) Late-life body mass index and dementia incidence: Nine-year follow-up data from the Kungsholmen Project. J Am Geriatr Soc 56, 111-116.

[31] Dahl AK, Löppönen M, Isoaho R, Berg S, Kivelä SL (2008) Overweight and obesity in old age are not associated with greater dementia risk. J Am Geriatr Soc 56, 2261-2266.

[32] Hughes TF, Borenstein AR, Schofield E, Wu Y, Larson EB (2009) Association between late-life body mass index and dementia The Kame Project. Neurology 72, 1741-1746.

[33] Luchsinger JA, Patel B, Tang M, Schupf N, Mayeux R (2007) Measures of adiposity and dementia risk in elderly persons. Arch Neurol 64, 392-398.

[34] Power BD, Alfonso H, Flicker L, Hankey GJ, Yeap BB, Almeida OP (2011) Body adiposity in later life and the incidence of dementia: The health in men study. PloS One 6, e17902.

[35] Fitzpatrick AL, Kuller LH, Lopez OL, Diehr P, O’Meara ES, Longstreth WT Jr, Luchsinger JA (2009) Midlife and late-life obesity and the risk of dementia: Cardiovascular health study. Arch Neurol 66, 336-342.

[36] Gustafson D, Rothenberg E, Blennow K, Steen B, Skoog I (2003) An 18-year follow-up of overweight and risk of Alzheimer disease. Arch Intern Med 163, 1524-1528.

[37] Hayden KM, Zandi PP, Lyketsos CG, Khachaturian AS, Bastian LA, Charoonruk G, Tschanz JT, Norton MC, Pieper CF, Munger RG (2006) Vascular risk factors for incident Alzheimer disease and vascular dementia: The Cache County study. Alzheimer Dis Assoc Disord 20, 93-100.

[38] Luchsinger JA, Patel B, Tang M, Schupf N, Mayeux R (2007) Measures of adiposity and dementia risk in elderly persons. Arch Neurol 64, 392-398.

[39] Atti AR, Palmer K, Volpato S, Winblad B, De Ronchi D, Fratiglioni L (2008) Late-life body mass index and dementia incidence: Nine-year follow-up data from the Kungsholmen Project. J Am Geriatr Soc 56, 111-116.

[40] Hughes TF, Borenstein AR, Schofield E, Wu Y, Larson EB (2009) Association between late-life body mass index and dementia: The Kame Project. Neurology 72, 1741-1746.

[41] Hayden KM, Zandi PP, Lyketsos CG, Khachaturian AS, Bastian LA, Charoonruk G, Tschanz JT, Norton MC, Pieper CF, Munger RG (2006) Vascular risk factors for incident Alzheimer disease and vascular dementia: The Cache County study. Alzheimer Dis Assoc Disord 20, 93-100.

[42] Neergaard JS, Dragsbaek K, Hansen HB, Henriksen K, Christiansen C, Karsdal MA (2016) Late-life risk factors for all-cause dementia and differential dementia diagnoses in women: A prospective cohort study. Medicine (Baltimore) 95, e3112.
[43] Gustafson D, Rothenberg E, Blennow K, Steen B, Skoog I (2003) An 18-year follow-up of overweight and risk of Alzheimer disease. Arch Intern Med 163, 1524-1528.

[44] Borenstein Graves A, Mortimer JA, Bowen JD, McCormick WC, McCurry SM, Schellenberg GD, Larson EB (2001) Head circumference and incident Alzheimer's disease: Modification by apolipoprotein E. Neurology 57, 1453-1460.

[45] Buchman AS, Wilson RS, Bienias JL, Shah RC, Evans DA, Bennett DA (2005) Change in body mass index and risk of incident Alzheimer disease. Neurology 65, 892-897.

[46] Scarmeas N, Luchsinger JA, Schupf N, Brickman AM, Cosentino S, Tang MX, Stern Y (2009) Physical activity, diet, and risk of Alzheimer disease. JAMA $\mathbf{3 0 2}$, 627-637.

[47] Yoshitake T, Kiyohara Y, Kato I, Ohmura T, Iwamoto H, Nakayama K, Ohmori S, Nomiyama K, Kawano H, Ueda K (1995) Incidence and risk factors of vascular dementia and Alzheimer's disease in a defined elderly Japanese population: The Hisayama Study. Neurology 45, 1161-1168.

[48] Power BD, Alfonso H, Flicker L, Hankey GJ, Yeap BB, Almeida OP (2011) Body adiposity in later life and the incidence of dementia: The health in men study. PloS One 6, e17902.

[49] Dahl AK, Löppönen M, Isoaho R, Berg S, Kivelä S (2008) Overweight and obesity in old age are not associated with greater dementia risk: (See editorial comments by Dr. David S. Knodman, pp 2349-2350). J Am Geriatr Soc 56, 22612266.

[50] Buchman AS, Schneider JA, Wilson RS, Bienias JL, Bennett DA (2006) Body mass index in older persons is associated with Alzheimer disease pathology. Neurology 67, 19491954.

[51] Nourhashemi F, Deschamps V, Larrieu S, Letenneur L, Dartigues JF, Barberger-Gateau P, PAQUID study Personnes Agees Quid (2003) Body mass index and incidence of dementia: The PAQUID study. Neurology 60, 117-119.

[52] Tolppanen AM, Ngandu T, Kåreholt I, Laatikainen T, Rusanen M, Soininen H, Kivipelto M (2014) Midlife and late-life body mass index and late-life dementia: Results from a prospective population-based cohort. J Alzheimers Dis $\mathbf{3 8}$, 201-209.

[53] Hughes TF, Borenstein AR, Schofield E, Wu Y, Larson EB (2009) Association between late-life body mass index and dementia The Kame Project. Neurology 72, 1741-1746.

[54] Emmerzaal TL, Kiliaan AJ, Gustafson DR (2015) 20032013: A decade of body mass index, Alzheimer's disease, and dementia. J Alzheimers Dis 43, 739-755.

[55] Zamboni M, Mazzali G, Zoico E, Harris TB, Meigs JB, Di Francesco V, Fantin F, Bissoli L, Bosello O (2005) Health consequences of obesity in the elderly: A review of four unresolved questions. Int J Obes 29, 1011-1029.

[56] Kivimäki M, Luukkonen R, Batty GD, Ferrie JE, Pentti J, Nyberg ST, Shipley MJ, Alfredsson L, Fransson EI, Goldberg M (2018) Body mass index and risk of dementia: Analysis of individual-level data from 1.3 million individuals. Alzheimers Dement 14, 601-609.

[57] Jura M, Kozak LP (2016) Obesity and related consequences to ageing. Age (Dordrecht, Netherlands) 38, 23.

[58] Visscher TLS, Seidell JC, Molarius A, van der Kuip F, Hofman A, Witteman JCM (2001) A comparison of body mass index, waist-hip ratio and waist circumference as predictors of all-cause mortality among the elderly: The Rotterdam study. Int J Obes 25, 1730-1735. 
[59] Zhang C, Rexrode KM, van Dam RM, Li TY, Hu FB (2008) Abdominal obesity and the risk of all-cause, cardiovascular, and cancer mortality: Sixteen years of follow-up in US women. Circulation 117, 1658-1667.

[60] de Koning L, Merchant AT, Pogue J, Anand SS (2007) Waist circumference and waist-to-hip ratio as predictors of cardiovascular events: Meta-regression analysis of prospective studies. Eur Heart J 28, 850-856.

[61] Anstey KJ, von Sanden C, Salim A, O’Kearney R (2007) Smoking as a risk factor for dementia and cognitive decline: A meta-analysis of prospective studies. Am J Epidemiol 166, 367-378.

[62] Luchsinger JA, Gustafson DR (2009) Adiposity, type 2 diabetes, and Alzheimer's disease. J Alzheimers Dis 16, 693-704.

[63] Biessels GJ, Staekenborg S, Brunner E, Brayne C, Scheltens P (2006) Risk of dementia in diabetes mellitus: A systematic review. Lancet Neurol 5, 64-74.

[64] Gudala K, Bansal D, Schifano F, Bhansali A (2013) Diabetes mellitus and risk of dementia: A meta-analysis of prospective observational studies. J Diabetes Investig 4, 640-650.

[65] Elias-Sonnenschein L, Viechtbauer W, Ramakers IHGB, Verhey FRJ, Visser PJ (2011) Predictive value of APOE-e4 allele for progression from MCI to AD-type dementia: A meta-analysis. J Neurol Neurosurg Psychiatry 82, 1149-1156.

[66] Knopman DS, Edland SD, Cha RH, Petersen RC, Rocca WA (2007) Incident dementia in women is preceded by weight loss by at least a decade. Neurology $\mathbf{6 9}$, 739-746.

[67] Flegal KM, Graubard BI, Williamson DF, Cooper RS (2011) Reverse causation and illness-related weight loss in observational studies of body weight and mortality. Am J Epidemiol 173, 1-9.
[68] Ancelin M, Ripoche E, Dupuy A, Samieri C, Rouaud O, Berr C, Carrière I, Ritchie K (2014) Gender-specific associations between lipids and cognitive decline in the elderly. Eur Neuropsychopharmacol 24, 1056-1066.

[69] Rantanen K, Strandberg AY, Salomaa V, Pitkälä K, Tilvis RS, Tienari P, Strandberg T (2017) Cardiovascular risk factors and glucose tolerance in midlife and risk of cognitive disorders in old age up to a 49-year follow-up of the Helsinki businessmen study. Ann Med 49, 462-469.

[70] Mehlig K, Lapidus L, Thelle DS, Waern M, Zetterberg H, Bjorkelund C, Skoog I, Lissner L (2018) Low fasting serum insulin and dementia in nondiabetic women followed for 34 years. Neurology 91, e427-e435.

[71] Nguyen JC, Killcross AS, Jenkins TA (2014) Obesity and cognitive decline: Role of inflammation and vascular changes. Front Neurosci 8, 375.

[72] Gustafson DR (2012) Adiposity and cognitive decline: Underlying mechanisms. J Alzheimers Dis 30, S97-S112.

[73] Zade D, Beiser A, McGlinchey R, Au R, Seshadri S, Palumbo C, Wolf PA, DeCarli C, Milberg W (2013) Apolipoprotein epsilon 4 allele modifies waist-to-hip ratio effects on cognition and brain structure. J Stroke Cerebrovasc Dis 22, 119-125.

[74] Anstey KJ, Cherbuin N, Budge M, Young J (2011) Body mass index in midlife and late-life as a risk factor for dementia: A meta-analysis of prospective studies. Obes Rev 12, e426-e437.

[75] Beydoun MA, Beydoun HA, Wang Y (2008) Obesity and central obesity as risk factors for incident dementia and its subtypes: A systematic review and meta-analysis. Obes Rev 9, 204-218.

[76] Fitzpatrick AL, Kuller LHDH, Lopez OL, Diehr P, O’Meara ES, Longstreth WTJ, Luchsinger JA (2009) Midlife and latelife obesity and the risk of dementia: Cardiovascular Health Study. Arch Neurol 66, 336-342. 